\title{
The Experience of Health Care Workers Infected by Corona Virus Diseases-19
}

\author{
Siti Rochanah ${ }^{1} \oplus$, Irma Nurbaeti $^{2^{*}}$ \\ 1 Jakarta Islam Hospital, Jakarta, Indonesia \\ ${ }^{2}$ Faculty of Health Sciences, Universitas Islam Negeri Syarif Hidayatullah Jakarta, \\ Tangerang, Indonesia
}

\begin{abstract}
Background: The number of health workers on the front lines have been affected by COVID-19 and some of them have been infected by COVID-19 since the outbreak of COVID-19. Understanding healthcare workers experience is important to get their meaning and expression.

Purpose: The purpose of this study is to explore the experiences of healthcare workers infected by COVID-19.

Methods: Qualitative phenomenological approach is carried out in this study with phenomenological analysis for data interpretation. Data collection was carried out by in-depth interviews with 12 health workers who were infected by COVID-19 both during treatment and after being treated at a non-government hospital in Jakarta, Indonesia.

Results: We found five themes followed by fourteen subthemes. The themes were (1) The meaning of COVID-19 for her/himself, (2) The first feelings of being infected by COVID-19, (3) Experience of Clinical symptoms, (4) Experience of psychological and social disorders, (5) Experience in accessing health services.

Conclusion: Health workers infected by COVID-19 have had several positive and negative experiences. This research can provide an in-depth understanding of the lives of health workers infected by COVID-19. Proper planning and support is important to reduce health worker problems both physically and psychologically.
\end{abstract}

Keywords: covid-19; experience; healthcare workers; phenomenological research.

\section{Introduction}

Corona Virus Disease 2019 (COVID-19) is the latest infectious disease that has never been identified in humans before. It has been declared by the World Health Organization (WHO) as a pandemic in March 2020 (WHO, 2020). Previously, the disease was referred to as the '2019 novel coronavirus' or '2019-nCoV.' (WHO, 2020). Indonesia announced the COVID-19 outbreak in the first week of March 2020 (Ibrahim et al, 2020). The spread and increase in the number of cases took place quite rapidly throughout the world in a short time, including Indonesia. This is because initially, the COVID-19 outbreak was reported as limited person-to-person transmission and the contaminated source of infected or sick wild animals in wet markets probably originated in Wuhan, China. But emerging evidence with clusters of outbreaks among families confirms the possibility of personto-person transmission. However, health workers as the front line have a high risk of being exposed to people infected with COVID-19 (Wu, Chen, \& Chan, 2019).

The Ministry of Health reported a daily increase in positive confirmed cases of COVID-19 with a Case Fatality Rate of $3.03 \%$ and a positive $18.1 \%$ (Ministry of Health of the Republic of Indonesia, 2020). The spread of COVID-19 causes an increase in morbidity and mortality. Therefore, the number of hospitalized patients suffering from COVID-19 has greatly increased. The rapid spread of the disease in early 2020 caught many 
health care systems off guard and rushed to provide intensive care unit beds, ventilators and personal protective equipment (PPE) for healthcare workers and patients.

The coronavirus disease 2019 (COVID-19) is spreading rapidly, bringing stress and challenges to healthcare workers who interact directly with patients in the workplace. With the pandemic, healthcare workers have faced a storm of conditions that threaten their health, well-being, and ability to do their jobs (Neto et al., 2020). The sudden spike in the COVID-19 pandemic as a new highly contagious case has made health services unprepared. Personal Protective Equipment is incomplete, health workers are not skilled and there is not enough training time to provide knowledge and skills in treating patients. Health workers put the risk of transmitting the virus. Transmission of COVID-19 to health workers is through nosocomial infection from closed direct contact and/or droplets (Wahyuningsih et al., 2020). According to WHO, more than $10 \%$ of healthcare workers are disproportionately affected by COVID-19.

Several studies have examined the condition of health workers related to their duties in dealing with COVID-19. For example, several researchers studied the psychological impact on health workers (Janitra et al., 2021; Torales et al., 2020; Widjadja et al., 2020). Another study shows that health workers are against stigma (Abudi et al., 2020). Challenges that health workers face in responding to COVID-19 include fatigue from prolonged use of personal protective equipment and heavy workloads, as well as fear of infection and transmission to others, while social support and self-management strategies help health workers cope with stress (Liu, 2020). High risk pressure and exposure to COVID-19 on health workers has caused many health workers to be infected with COVID-19.

This condition causes physical, psychological, social and religious impacts for health workers when they become patients infected with Covid 19. What they are experiencing can have an impact on fellow health workers who treat Covid patients, can cause or increase feelings of fear that can interfere with their role in providing health services, even though at the same time their role is very much needed in situations of a pandemic spike.

Several previous studies conducted qualitative research on the experience of being infected with COVID-19 in Indonesia. Aungsuroch studied the experience of corona virus sufferers in the pandemic era in Indonesia with the subject as a general patient, not a health worker as a patient (Aungsuroch, Juanamasta, Gunawan, 2020.) Another study on the stigma against health workers related to their work in treating COVID-19 patients (Abudi et al., 2020). However, research is limited to the experiences of health workers infected with COVID-19 in Indonesia. The COVID-19 pandemic is a new, highly contagious outbreak, not much is known and it is important to address it immediately. However, the need for information about the experiences of health workers infected with COVID-19 is important. In addition, the important role of these health workers is to immediately return to work as the front line in overcoming the surge in the COVID-19 pandemic.

The voice of health workers is important to be heard. An in-depth understanding of the lives of health workers infected with COVID-19 is required, especially to gain new knowledge and sensitivity in providing holistic prevention, care and health services. Therefore, the purpose of our research is to explore in depth the life experiences of health workers who have been infected with COVID-19.

\section{Methods}

A qualitative method with an interpretive phenomenological approach is used in this study. This study was conducted at a hospital in Jakarta, Indonesia during June to July 2020. Twelve participants who were confirmed positive for COVID-19 involved in this study were selected using a purposive sampling technique. Data saturation was achieved in the eleventh participant. Inclusion criteria: health workers diagnosed with COVID-19, willing to participate as participants and able to share their experiences well/cooperatively.

The data collection process includes 2 stages: the first stage is research procedures related to obtaining research administration permits including research permits to hospitals and ethical approvals. Ethical approval was obtained from hospital number $015 / \mathrm{V} / 2020 / \mathrm{KE}$. The second stage is the data collection strategy. After obtaining ethical approval from the ethics committee and a research permit from the hospital, the process of selecting participants was carried out. The researchers were assisted by the team of the Hospital Risk Management Quality Committee to select the initial participants.

Participants are hospitalized or have completed hospitalization or self-isolation within 14-55 days. All of the participants had experienced mild, moderate and severe stress as indicated by complaints of stress during the interview. However, these participants can still receive direction from other parties, both from management, the health team and other family members.

\section{Collecting data}

Data were collected using in-depth interview techniques. Each participant was interviewed in depth for approximately 60-90 minutes according to their condition and gradually. In-depth interviews were conducted using an interview guide. Openended follow-up questions were used to obtain detailed descriptions, and examples were:"what is the meaning of COVID-19 to you?"; "how did you feel on the first day of being confirmed by COVID-19"; "how are you feeling now"; "what challenges did you encounter"; "how did you respond"; "what external support have you received"; and "what is 
the plan after recovering from COVID-19?" Probing questions, such as "Please tell me more about that", were used to enhance the depth of discussion.

Observations were made on some of the participants who had finished treatment by observing the participants' expressions such as facial expressions, body language and various reactions of participants when speaking related to the participant's statements given and the environmental situation during the in-depth interview process. Researchers as the main research instrument are also assisted by other data collection instruments, namely in-depth interview guidelines, field notes and cellphones as voice recording devices or as chat interviews.

\section{Data Analysis}

Haase's adaptation of the Colaizzi method was used to analyze the transcripts. The analysis included reading the transcript several times to gain an understanding of meanings conveyed, identifying significant phrases and restating them in general terms, formulating meanings and validating meanings through research team dis- cussions to reach consensus, identifying and organising themes into clusters and categories, and developing a full description of themes.

Several strategies were used to ensure trustworthiness and credibility. Credibility was achieved by in-depth interviews followed by peer debriefing. Two co-authors analysed the transcripts independently by bracketing data on preconceived ideas and strictly following the adapted Colaizzi's method described above. Findings were then compared and discussed by the team until consensus was achieved on themes, theme clusters, and categories. Transferability was established by considering variations of participant characteristics and sufficient quotations collected through in-depth interviews. The audit trail was maintained to ensure all analysis steps could be traced back to original interviews.

\section{Results}

\section{Overview of the participants:}

A total of twelve health workers participated in this study. They consisted of two males and ten females. Health workers consisted of one radiologist, one general practitioner, five nurses and five midwives. Their ages varied from 23 years old to 48 years old. All participants were permanent employees of a type B hospital in Jakarta. Two participants were unmarried, the others were married and had children and spouses. Only one participant has a bachelor's level of education, namely a doctor and eleven others with a three-diploma education. Regarding the health status of the participants, one person with comorbid hypertension was regularly controlled for treatment and consumption of antihypertensive drugs. The other eleven participants had no comorbidities. The length of time participants experienced COVID-19 was between 14 days to 55 days.

This research raised five themes as follows 1) The meaning of COVID -19; 2) The feeling of being infected by the COVID-19 for the first time; 3) Clinical symptoms established; 4) Psychological and social status; and 5) Access to health services.

\section{Theme 1: The meaning of COVID -19}

The meaning of COVID-19 as an infectious disease was perceived by all informants. Based on literature, COVID-19 is an infectious disease caused by a new type of Coronavirus. In the early spreading of COVID-19, there was limited information and knowledge about COVID-19. All participants said that COVID-19 was an infectious disease that spread quickly and mentally impacted to infected people. All participants said that COVID-19 was a contagious disease caused by a new virus but there was a little information in early 2020 . All participants had knowledge about virus from television or social media. The virus was related to immune system as they said that it was transmitting quickly but not a killer disease as long as the host had a good immune system.

COVID-19 emerged and existed out there. Meanwhile, for victims it tended to cause mental and psychological impact.

" .... believe there is an outbreak of the COVID-19 disease that really exists". (P2)

Also, four informants said that COVID-19 was a pandemic disease that had a more psychological or mental impact than physical, while vaccine in the first outbreak was not found yet, resulting in uncertain condition of thought.

".... COVID-19 is just like the influenza virus, transmitting quickly but not deadly, as long as the immune system is fine..."( $\mathrm{P} 1)$

" ... pandemic disease that has a more psychological impact...."(P4)

" .....virus outbreak attacking the immune system and there is no vaccine yet ..." (P10) and four participants said that COVID-19 can cause death or not depending on immunity.

".... infectious disease that can be deadly or just a common disease". (P12)

\section{Theme 2: The feeling of being infected by the COVID-19 for the first time}

The findings show that when participants were first confirmed with COVID-19, they felt shock, sadness, and uncertainty.

\section{Shock}

Nine participants were shocked when they first obtained the reactive rapid test or antigen swab, even though reactive and antigen swab were not an exact diagnosis. This feeling occurred because the majority of participants felt healthy when being tested. They had no severe symptoms and complaint so they imagined the results of either the rapid test or antigen swab was non-reactive. Four of 
the participants had mild symptoms such as unusual cough and flu. They felt shocked and not ready to be diagnosed with COVID-19, also felt guilty to go back home. Some of participants' expressions were:

".... shocked because (I) rarely get near to the patient, how come you can get it" (P5)

"... shocked, I have no energy to walk to home". "... shock, until tears" (P3)

"Shocked, can't believe it, maybe wrong laboratory results because there are no symptoms" (P6)

\section{Sadness}

All participants felt sad when they knew they were infected with COVID-19. Their sadness was caused by some factors, such as feeling unwell, being far away from their family, and particularly because it was in fasting month and they were worried about their child. The sadness was expressed by crying. It was expressed:

"I was sad, feeling unwell," (P1)

".... very sad, trembling". "Sad, leaving my child, because I was never far from my child, especially during the fasting month". "...Sad, it can hurt a long time". "... very sad, until crying" (P3)

\section{Uncertainty}

The result found that three of twelve participants felt a sense of uncertainty the first time. Being infected with Covid-19, knowing the positive result of the rapid test or swab, this uncertain feeling is caused because some of them are without symptoms or with mild symptoms. At that time, vaccine for COVID-19 was not established yet. These were participants' expressions:

"..... mixed feelings, uncertain thoughts".

"...Confused, like mixed vegetables (in Bahasa Indonesia: gado-gado)"(P1)

"...Confused and confused". ".... Feeling drop, crying and feeling mixed"(P3)

\section{Theme 3: Clinical symptoms established}

COVID-19 infection causes mild to severe symptoms, such as fever, runny nose, cough, shortness of breath, and anosmia as specific signs. And sometimes infected people have no symptoms.

\section{Physical symptom}

Nine participants experienced physical symptoms of COVID-19 like the influenza virus: fever, cough, flu, dizziness and fatigue. Three of the participants had experienced a fever during their illness, as follows:

".... I had fever and chills." (P8)

"...fever fluctuates in ten days". (P7)

Four participants experienced physical symptoms of coughing as follows:

"...Coughing for a long time, almost two months". (P7)

"...Cough also sputum". (P5)

Three of the participants felt flu, along with the expression:
(P4)

“... flu for many days and can't smell anything”.

“...Not really ordinary flu, only at any time”. “... runny nose"(P7)

One participant felt shortness of breath

"My condition was getting worse, I felt short of breath, I used an oxygen and bedrest" (P12)

While three participants felt both dizziness and headache because of the symptoms of the disease as well as the effects of the drug, as follows:

"...Headache and nausea" (P9)

"...Dizziness, heavy headache when taking Chloroquine (medicine)" (P5)

Another physical symptom was fatigue. One participant experienced physical fatigue and felt no energy. Following was one of the participants' expressions:

"The body feels tired, weak and ache" (P7)

\section{Having no symptoms}

COVID-19 does not always cause symptoms. Three participants had not complaint about physical symptoms.

“.... absolutely no complaints”. (P2)

“....no complaints, I even have asthma”. (P1)

\section{Theme 4: Psychological and social status}

Being infected by COVID-19 generated psychological and social disturbances. Participants felt psychological and social impact as follows: stress, shame, annoyance and resignation. Fortunately, as health workers, they had a positive coping, self-confident of being recover soon and ready to work again.

\section{Stress}

All participants experienced stress during illness from a mild, moderate or severe level related to physical complaints, examination results, length of recovery, side effects of therapy, information on the death of health workers due to COVID-19, being afraid of death threats and public views. We got their concerns:

"... at first I didn't get stressed, but when I took the medicine there was an effect of nausea and my body wasn't feeling well, so it made me stressed"(P8)

"...stressed, afraid to die because shortness of breath" (P12)

"...increasing of feeling down while hearing the medical personnel dropping" (P7)

One participant felt stressed because of feeling guilty about another people's view.

“...Stressed because of people's views" (P1)

\section{Shame}

Four participants said shame was related to the social impact of their illness, as follows:

"Shame, not confident to leave the house, because I see it.".(P3)

"Shame, because people's views seem embarrassing" (P1)

"Shame, like being hit by the plague, because 
the neighbors avoided"(P6)

Feelings of shame will be reduced because participants were able to adapt to conditions along with the length of illness and because there was a lot of support from friends and family and neighbors. The following expressions of two participants were: (P1)

"...l used to be embarrassed ... not anymore".

“...In fact, now my neighbors are asking many questions"(P8)

\section{Exasperated}

Four participants felt annoyed, this happened because they felt they had tried to comply with the COVID-19 prevention protocol, but they still caught it. They felt that they adhered to the protocol and therapy but the swab results were still positive many times. Other things that annoyed them were the length of isolation and the length of the examination results.

"I was really annoyed to the patient who transmitted it, I grumbled to myself"(P7)

"Initially I was annoyed, it took a long time to get a negative result, again positive, eagerly waiting for the result"(P1)

"Annoyed, tired of the isolation over time"(P7)

\section{Feeling of giving up}

The emotional state caused by the Covid-19 disease made participants sad, embarrassed and annoyed. In the condition of the disease that did not result in a negative swab, eventually all the participants gave up. This was stated by all participants.

"Finally I surrendered, just surrendering to Allah's destiny". (P12)

"Had time to ask in vain, why Allah, why? Finally thought all was a test and really surrendered myself" (P9)

"This is a warning from Allah, in the past life was happy and happy, now there are favors that are revoked, resigned" (P1)

\section{Self-confident}

All participants felt confident to recover from COVID-19. Some of them experienced mild symptoms and some had no symptoms at all. One participant who had moderate symptoms, felt confident too when he got better. They get confident for recovering from illness.

"...Sure can be cured, many peoples were healed"(P8)

“...already no complaints, sure to recover"(P2)

"I was afraid to die when I had breathing difficulty, but slowly it got better and I started to believe myself to be healed" (P12)

\section{Positive coping}

All participants had positive coping, by increasing immunity, while some others get positive coping by religious practice, such as reciting Koran, prayer, dhikr and dhua'.

"...Keep the immune, think positively" (P10)

"Praying, reading the Koran and its meaning, it's already read juz 20" (P1)

"I think positively after all treatment" (P12)

\section{Ready to work}

All participants as health workers felt ready to work again after recovering, following their expressions:

"...Ready to get back to the hospital, even though there is a worry of getting re-infected"(P12)

".... ready to work, I even want to work in the COVID' room, so I can share and give motivation to patients".(P8)

".. After recovering, if God willing, I will work again" (P1)

Theme 5: Access to health services.

It was easy for all participants to be admitted to the hospital. They experience easy access to health services and strong support.

1. Satisfactory health services

All participants felt satisfied with service while hospitalized. They get a good health care.

"...All praise be to Allah, be served well"(P1)

"...The service is good, but if you get chloroquine, it is safer if there are officers watching it because there are side effects of the medicine, measured vital sign and apply ECG. (P5)

"...The service is good, especially if there is an evaluation after returning home"(P8)

2. Getting strong support

All participants felt a lot of support from family, friends and management team since they started isolation, treatment and when they went back to work. Here was their expression:

"...My husband goes to hospital almost every night, even though it is far away" (P3)

"...My children pray, Mama don't die"(P6)

"a lot of support including management" (P12)

\section{Discussion}

The purpose of this study was to explore more deeply about the life experiences of health workers who have been infected with COVID-19 while living their daily lives with the disease. We identified five themes in this study, which can be also considered as the stage of the process of those with COVID-19 from the first response until acceptance and readiness to work again.

The meaning of COVID -19 as an infectious disease that is perceived by all informants is in accordance with all literature discussing the meaning of COVID-19. COVID-19 is an infectious disease caused by a new type of Coronavirus. COVID-19 is a contagious disease caused by Severe Acute Respiratory Syndrome Coronavirus 2 (SARS-CoV-2) (Ministry of Health the Republic of Indonesia, 2020). The understanding about COVID-19 at that time is still limited because SARS- 
CoV-2 is a new type of Coronavirus that has never been identified in humans before.

The results showed that psychological responses were feelings of shock, sadness and uncertainty when participants were first diagnosed with COVID-19. All informants felt shocked according to their circumstances. Informants who actively took care of the patients with confirmed COVID-19 were a little surprised because they had a better understanding of the risk of transmission and how the transmission of COVID-19 occurred. Other informants felt that they did not have direct contact with patients who were positive or with mild symptoms. Participants understood that transmission can occur due to direct contact with people without symptoms or due to indirect contact with unknown source of transmission. This response in line with Kubler-Ross, which stated that feelings of shock is the first psychological response to unpreparedness in facing something or not accepting the reality that happened (KublerRoss in Potter and Perry, 2013). In general, no one is ready to get sick, including with COVID-19. The results of this study are in accordance with research by Aungsuroch et al. (2020) that even the subject of lay patients, the patients felt shocked as an initial response to diagnosis of COVID-19. There is no difference in the psychological response either as a layperson or as a health worker when diagnosed with COVID-19.

Feelings of uncertainty can occur for several reasons. First, it relates to the limited understanding of this disease. COVID-19 is a new disease and has not been recognized in routine practice by health workers. Information about this virus from January to July 2020 is still very limited because many things are being researched. Feelings of uncertainty are also related to understanding the impact of the COVID-19 disease, such as being highly contagious, can be deadly, isolation or treatment is long and there is a negative response from the community. This condition makes individuals continue to seek additional information.

Furthermore, participants also felt sadness. Feeling sad is the next stage of the grieving process, naturally occurs after someone experiences denial, in this case feeling shocked, uncertain. During this stage, the individual begins to understand certainty, because of this the individual weeps and grieves. They are scared of stigma. It happened in the early COVID-19 outbreak. Wahyuningsih et all (2020) found that nurses should have good preparation to reverse COVID-19 both physically and psychologically.

The results of the symptoms of being infected with COVID-19 are fever, cough, flu, shortness of breath, dizziness, fatigue, anosmia and even no symptoms. The results of this study are in accordance with the concept that the symptoms experienced are usually mild and appear gradually. Some infected people do not show any symptoms and still feel well. This is in accordance with research that the most common symptoms of COVID-19 are fever, fatigue, and dry cough. Some patients may experience aches and pains, nasal congestion, runny nose, shortness of breath, headache, conjunctivitis, sore throat, diarrhea, loss of smell or skin rash.

A study by Du Z et. Al. (2020) reported that $12.6 \%$ patients diagnosed COVID-19 exhibited presymptomatic transmission. According to data from countries affected by the pandemic, in the beginning it showed that $40 \%$ of cases would develop mild disease and $40 \%$ would develop moderate disease including pneumonia, $15 \%$ of cases would develop severe illness, and $5 \%$ of cases would develop critical condition (Susilo, 2020).

The incubation period for COVID-19 is between 3-14 days. It is characterized by leukocyte and lymphocyte levels that are normal or slightly decreased, and the patient has not felt the symptoms. Subsequently, the virus begins to spread through the bloodstream, mainly to ACE2-expressing organs and the patient begins to experience mild symptoms. In humans, SARS-CoV-2 primarily infects cells in the airways lining the alveoli. Infections of the respiratory tract can cause coughing and flushing. Fever occurs in an inflammatory process due to viral invasion. Decreased endurance and prolonged illness can cause fatigue. Four to seven days from the initial symptoms, the condition begins to worsen marked by the onset of shortness of breath, decrease and worsening of the lesions in the lungs. If this is not resolved, acute respiratory distress syndrome (ARDS), sepsis and other complications can occur. (Susilo et al, 2020).

The themes of psychological and social status were stress, shame, annoyance, resignation, positive coping, self-confidence to recover and readiness to work again. Explicitly, the participant's stress expression was found. A pandemic condition and being diagnosed with COVID-19 were events that cause of stress. This is in accordance with the statement of Asmundson et al (2020) that a life event can be a source of stress to someone if the incident requires behavioral adjustments in a very short time especially in COVID-19 pandemic. In line with that, Kaligis et all (2020) stated that pandemic COVID-19 had an impact on mental health condition in Indonesia, particularly stress.

Stress begins with anxiety that has existed since the beginning of caring for patients in a pandemic situation. This is in accordance with the results of several studies, namely research using a surveybased study of mental health from 1,257 health workers who treat COVID-19 patients in 34 hospitals in China. As a result, most of them reported $50 \%$ depressive symptoms, $45 \%$ anxiety, $34 \%$ insomnia and $71.5 \%$ psychological distress (Lai et al, 2020). Another study found during the acute SARS outbreak that $89 \%$ of health workers were at high risk of experiencing symptoms of psychological disorders, one of which was anxiety (Chua et al, 2014).

Some factors can be as a source of stress 
or anxiety for health workers. The results of the study Fadli et al (2020) stated that family status, patient honesty, availability of personal protective equipment and knowledge had an effect on health workers' anxiety. Stress conditions increased due to various reasons of the participants, namely physical discomfort, side effects of therapy and information on the death of health workers. The existence of the bad stigma of COVID-19 as an infectious disease and the acceptance of negative responses from some of the people living around their homes creates feelings of shame because they feel rejected by the community. This makes some of them feel isolated even though they have been declared cured and returned home. Participants also understood that other people try to avoid contact with patients and family members. There is a negative stigma towards people infected with COVID-19, especially health workers suspected of carrying the virus. Health workers are victims of stigma (Abudi et al, 2020). Negative stigma arises because of limited public information about the COVID-19 healing process and the large number of hoaxes circulating in social media. Feelings of shame are only temporary, diminished by the large amount of support from family, community and co-workers.

Feelings of annoyance are manifestations of despair, rejection and expressions of angry feelings. Some participants felt annoyed because they felt they had tried to comply with COVID-19 prevention protocols and therapy, but they were still infected and recovered for a long time. They felt bored in treatment and isolation. The feeling of annoyance increased with the information that there were still many people who did not comply with the health protocol.

In dealing with a disease that did not immediately heal, in the end the participants felt resigned to accept the reality of their illness. Individuals have to work hard through the process until they finally reach the acceptance stage. Surrender means surrendering to Allah by making optimal treatment efforts. They are closer to God and this is the most important value in all aspects of medicine. This result was consistent with Aungsuroch's (2020) research finding. Aungsuroch found the theme of self-reflection with God in patients with COVID-19. Surrender increases the patient's self-awareness with its creator and is a source of self-strength.

Coping involves trying to manage stressful situations, expanding efforts to solve life's problems, and working to cope with and reduce stress. Success in coping is associated with a number of characteristics, including an appreciation of personal control, positive emotions, dealing with situation, and personal resources (Shanafelt, 2020). Health worker participants generally have strong personal resources. They immediately look for updated information about COVID-19, used to educate patients, get convenience in receiving education and comply with health instructions given. Positive coping that is done is to think positively, worship more, maintain personal hygiene, get plenty of rest, sunbathe, eat nutritiously and comply with health protocols (Sanafelt, 2020).

Self-confidence is a positive emotion. Selfconfidence is a person's belief in all aspects of one's strengths and this belief makes him feel capable of achieving his goals in life. A person who has positive emotions can adapt well in traumatic situations (Asmundson, 2020). In this study, the strong confidence of the participants may relate to the large number of supportive resources, symptom of mild condition and the good progress of disease improvement.

The sub-theme of readiness to return to work shows a strong belief that they will recover and can work again as health workers which is their chosen profession. Readiness to work again is influenced by family support and management during illness and recovery. Working again will also eliminate boredom during treatment. The experience as a patient motivates them to recover quickly and help others through their work as health workers.

The results of research on the experience of health workers with COVID-19 in accessing health services indicate their satisfaction with health services and expectations of better services. Satisfaction with health services is reflected even though COVID-19 is a new disease, hospitals and health workers have made efforts to prepare adequate health care facilities to provide the best service in acute conditions. Participants generally have a strong assumption that good treatment will accelerate healing. They immediately search for the nearest health service to access. For health workers who are sick, of course it is easier to get health services, especially in their workplaces as well as other hospitals if a referral is needed. The strong support sub-theme was felt by the participants. As individuals and workers in stressful conditions, they really need support from other parties, especially family, colleagues, professions, management and the government.

This study provides new information about the experiences of health workers infected with COVID-19. This research helps to understand the mental processes and symptoms of pain experienced by participants. Participants without symptoms to mild symptoms of COVID-19 generally experienced more psychological than physical problems during illness. They experience stages of the grieving process mixed with other psychological problems ranging from shock responses, feelings of uncertainty, sadness, stress, shame, annoyance, resignation to acceptance and positive coping. In this study it was also found that participants did not experience feelings of uncertainty, were not irritated and did not feel ashamed. This condition is related to the speed of recovery and good acceptance in the community.

Health workers as the frontline in fighting the COVID-19 pandemic must take care of themselves. Various pressures and demands will affect their 
health and morality. Psychosomatic approaches are important for maintaining the health of health workers (Fadli et al, 2020). It is very important for patients to achieve immediate recovery and assistance from all parties to overcome their physical, psychological and social burdens.

The strength of this study is that it provides new knowledge about the experience of health workers infected with COVID-19 in depth for the first time by involving 12 participants in this study. The limitations of this study are the factors that are relative to being infected with COVID-19 and the factors that support resilience from being infected with COVID-19 have not been studied.

\section{Conclusion}

The life experience of health workers infected with COVID-19 consists of five themes, namely: the meaning of COVID-19, the experience of being infected for the first time, the experience during clinical symptoms, the experience of psychological and social disorders, and the experience of accessing health services. The findings of this study can be used as a reference to improve the management and care of COVID-19 in hospitals physically, psychologically and socially. Effective management is needed to reduce physical complaints and treat the diseases. Prevention and isolation of COVID-19 is very important to reduce the risk of transmission, speed up recovery and adapt to their lives biologically, psychologically, socially and spiritually.

\section{Acknowledgments}

The authors would like to express gratitude the Director of the Hospital and all the participants who participated in this study.

\section{References}

Abudi, R., Mokodompis, Y., \& Nurfadias, A. (2020). Stigma terhadap orang positif COVID-19. Jambura Journal of Health Sciences and Research, 2(2): 77-84. https://doi. org/10.35971/jjhsr.v2i2.6012

Asmundon, G., Paluszek, M.M, Landrya, C. A., Rachor, G. S., McKay, D., \& Taylor, S. (2020). Do pre-existing anxiety-related and mood disorders differentially impact COVID-19 stress responses and coping? Journal of Anxiety Disorders, $74 . \quad \mathrm{https} / / / \mathrm{doi} . o r g / 10.1016 / \mathrm{j}$. janxdis.2020.102271

Aungsuroch, Y., Juanamasta, I.G., Gunawan, J. (2020). Experience of patient with coronavirus in the COVID-19 pandemic era in Indonesia. Asian J Public Open Res, 8, 377-392. https:// doi.org/10.15206/ajpor.2020.8.3.377

Chua, S. E., Cheung, V., McAlonan, G. M., Cheung, C., Wong, J. W., Cheung, E. P., Chan, M. T., Wong, T. K., Choy, K. M., Chu, C. M., Lee, P. W., \& Tsang, K. W. (2004). Stress and psychological impact on SARS patients during the outbreak. Canadian journal of psychiatry, 49(6), 385-390. https://doi. org/10.1177/070674370404900607

Du, Z., Xu, X., Wu, Y., Wang, L., Cowling, B. J., \& Meyers, L. A. (2020). Serial interval of COVID-19 among publicly reported confirmed cases. Emerging Infectious Diseases, 26(6), 1341-1343. https://doi.org/10.3201/ eid2606.200357

Fadli, F., Safruddin, S., Ahmad, A.S., Sumbara, S., Baharuddin, R. (2020). Faktor yang mempengaruhi kecemasan pada tenaga kesehatan dalam upaya pencegahan COVID-19. J Pendidik Keperawatan Indonesia, 6(1), 57-65. https://doi.org/10.17509/jpki. v6i1.24546

Ibrahim, F., Natasha, A., Saharman, Y. R., \& Sudarmono, P. (2020). Preliminary report of COVID-19 testing: experience of the clinical microbiology laboratory Universitas Indonesia, Jakarta, Indonesia. New Microbes and New Infections, 37, 100733. https://doi. org/10.1016/j.nmni.2020.100733

Janitra, F. E., Melastuti, E., \& S, A. Y. (2021). Perceived stigma, psychological response, and nurse coping in the COVID-19 pandemic in Indonesia. Jurnal Keperawatan Padjadjaran, 9(1), 10-17. https://doi.org/10.24198/jkp. v9i1.1561

Kaligis, F., Indraswari, M. T., \& Ismail, R. I. (2020). Stress during COVID-19 pandemic: mental health condition in Indonesia. Medical Journal of Indonesia, 29(4), 436-441. https://doi. org/10.13181/mji.bc. 204640

Lai, J., Ma, S., Wang, Y., Cai, Z., Hu, J., Wei, N., Wu, J., Du, H., Chen, T., Li, R., Tan, H., Kang, L., Yao, L., Huang, M., Wang, H., Wang, G., Liu, Z., \& Hu, S. (2020). Factors Associated With Mental Health Outcomes Among Health Care Workers Exposed to Coronavirus Disease 2019. JAMA network open, 3(3), e203976. https://doi. org/10.1001/jamanetworkopen.2020.3976

Liu, Q., Luo, D., Haase, J. E., Guo, Q., Wang, X. Q. Liu, S., Xia, L., Liu, Z., Yang, J., \& Yang, B. X. (n.d.). Articles The experiences of health-care providers during the COVID-19 crisis in China : a qualitative study. The Lancet Global Health, 8(6), e790-e798. https://doi.org/10.1016/ S2214-109X(20)30204-7

Ministry of Health, The Republic of Indonesia (2020). COVID 19 dalam angka. Retrieved March 03, 2021, from https://www.kemkes.go.id/ resources/download/info-terkini/covid $\% 20$ dalam\%20angka/covid-19-dalam-angka-22agustus-2020.pdf

Neto, M. L. R., Almeida, H. G., Esmeraldo, J. D., Nobre, C. B., Pinheiro, W. R., de Oliveira, C. R. T., Sousa, I. da C., Lima, O. M. M. L., Lima, N. N. R., Moreira, M. M., Lima, C. K. T., Júnior, J. G., \& da Silva, C. G. L. (2020). When health professionals look death in the eye: the 
mental health of professionals who deal daily with the 2019 coronavirus outbreak. Psychiatry Research, 288. https://doi.org/10.1016/j. psychres.2020.112972

Nguyen, N., Le, D. D., Colebunders, R., Siewe Fodjo, J. N., Tran, T. D., \& Vo, T. V. (2021). Stress and Associated Factors among Frontline Healthcare Workers in the COVID-19 Epicenter of $\mathrm{Da}$ Nang City, Vietnam. International journal of environmental research and public health, 18(14), 7378. https://doi. org/10.3390/ijerph18147378

Shanafelt, T., Ripp, J., Sinai, M., \& Trockel, M. (2020). Understanding and Addressing Sources of Anxiety Among Health Care Professionals During the COVID-19 Pandemic. JAMA, 323(21): 2133-2134. https://doi.org/10.1001/ jama.2020.5893

Susilo, A., Rumende, C.M., Pitoyo, C., et al. (2020). Coronavirus Disease 2019: Tinjauan Literatur Terkini Coronavirus Disease 2019: Review of Current Literatures. Jurnal Penyakit Dalam Indonesia, 7(1): 45 - 67. http://dx.doi. org/10.7454/jpdi.v7i1.415

Torales, J., Higgins, M. O., Castaldelli-maia, J. M., \& Ventriglio, A. (2020). The outbreak of COVID-19 coronavirus and its impact on global mental health. International Journal of Social Psychiatry, 66(4): 317 - 320 . https://doi. org/10.1177/0020764020915212

Wahyuningsih, I. S., Janitra, F. E., Hapsari, R., Sarinti, S., Mahfud, M., \& Wibisono, F. (2020). The nurses' experience during the caring of Coronavirus (COVID-19) patients: A descriptive qualitative study. Jurnal Keperawatan Padjadjaran, 8(3), 255-263. https://doi.org/10.24198/jkp.v8i3.1559
Widjaja, F., Shatri, H., Putranto, R. (2020). Health issues among healthcare workers during COVID-19 pandemic: A psychosomatic approach. Acta Medica Indonesiana, 52(2),172-176. Retrieved March 03, 2021, from http://www.actamedindones.org/index. php/ijim/article/view/1459/pdf

World Health Organization (2020, March 12). WHO announces COVID 19 Outbreak a pandemic. Geneva, Switzerland: World Heaalth Organization. Retrieved March 2, 2021, from https://www.euro.who.int/en/health-topics/ health-emergencies/coronavirus-covid-19/ news/news/2020/3/who-announces-covid-19outbreak-a-pandemic

World Health Organization., (2020, July 9). Transmission of SARS-CoV-2: implications for infection prevention precautions. March, 1-10. Retrieved March 2, 2021, from https:// www.who.int/news-room/commentaries/detail/ transmission-of-sars-cov-2-implications-forinfection-prevention-precautions

World Health Organization (2020). Coronavirus info. Geneva, Switzerland: World Health Organization. Retrieved March 02, 2021, from https://www.worldometers.info/coronavirus/

World Health Organization. (2020, March 11). WHO Director-General's opening remarks at the media briefing on COVID- 19. World Health Organization. Retrieved March 2, 2021, from https://www.who.int/director-general/ speeches/detail/who-director-general-sopening-remarks-at-the-media-briefing-oncovid-19---11-march-2020

Wu, Y., Chen, C., \& Chan, Y. (2019). The outbreak of COVID-19: An overview. J Chin Med Assoc, 83: 217-220. https://doi.org/10.1097/JCMA. 